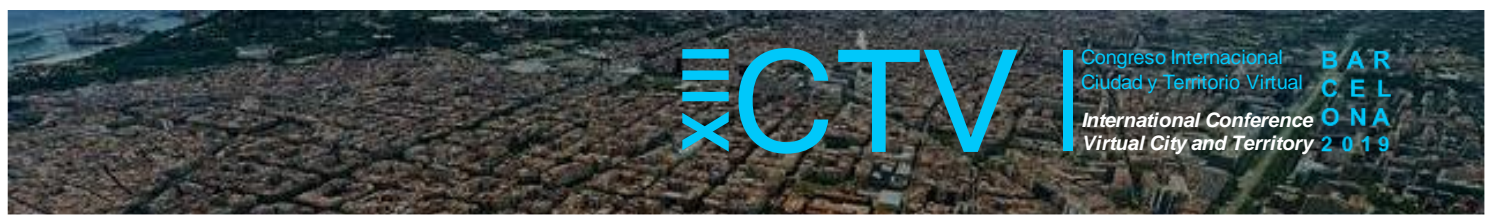

\title{
ESTRUCTURA, IMAGEN URBANA, TRANSPORTE Y MOVILIDAD A TRAVÉS DE LOS AÑOS EN GUAYAQUIL.
}

\author{
Naranjo, Yelitza ${ }^{1 *}$; Arellano, Blanca ${ }^{2}$; Roca, Josep ${ }^{3}$ \\ Remisión inicial: 2019-05-31; Remisión definitiva: 2019-09-24; Publicación: 2019-12-21
}

Citación: Naranjo, Y. et al. (2019). Estructura, Imagen Urbana, Transporte y Movilidad a través de los años en Guayaquil. En XIII CTV 2019 Proceedings: XIII International Conference on Virtual City and Territory: "Challenges and paradigms of the contemporary city": UPC, Barcelona, October 2-4, 2019. Barcelona: CPSV, 2019, p. 8475. E-ISSN 2604-6512. DOI http://dx.doi.org/10.5821/ctv.8475

\section{Resumen}

Todo proceso de renovación urbana genera un impacto a nivel social, físico, económico, ambiental y depende de las particularidades del contexto el definir las estrategias más apropiadas para desarrollar un proyecto, sobre todo los que están ligados directamente al transporte en las ciudades (Naranjo, Y \& Arellano, B., 2018).

Guayaquil y su transporte urbano han estado ligados al crecimiento de la ciudad a raíz del incremento de su población y de su economía a fines del siglo XIX. La ciudad y su centro estuvieron sometidos a un proceso de densificación comercial a partir de la década de los sesenta. Previamente su relación con el río Guayas, razón fundamental de su creación y existencia, lo que dejó de ser vital por la disminución de las actividades económicas que se desarrollaban a las orillas del río. Todos estos acontecimientos asociados a una creciente migración de la población hacia los nuevos barrios residenciales desarrollados en la periferia, y que sentaron bases para una disminución del centro de la ciudad, limitándose en gran parte a las actividades comerciales bancarias y públicas.

En el año 2006 el Municipio de Guayaquil, implementó el sistema integral de Transporte Masivo Urbano "Metrovía" y la ciudad empezaba a estar sometida a nuevas transformaciones físicas, en este caso con la implementación del nuevo sistema de transporte público masivo, que corresponde a un sistema BRT (Bus Rapid Transit) presentado con visiones sostenibles, es decir reducción de congestionamiento vehicular, movimiento de mayor cantidad de pasajeros y en menor tiempo que los buses urbanos, reducción de la contaminación ambiental y confort en su desplazamiento.

Como objetivo principal se plantea analizar el impacto y cambios que se han dado en la estructura urbana de Guayaquil con el transporte, una investigación que pretende entender justificadamente los parámetros mencionados anteriormente, a su vez el afán por conocer la movilidad de la ciudad como principal actor del espacio público, la forma como las personas se sitúan y trasladan de un lugar a otro a pie, en bicicleta o en un sistema de transporte masivo.

La metodología utilizada es cualitativa - descriptiva, con fuentes de información que plantea una revisión del "Plan de movilidad de Guayaquil" actual, las metas y acciones que se han establecido y hasta qué punto han sido implementadas o desarrolladas, así como contrastar con los objetivos que el Gobierno ha planteado en el documento público del "Plan del Buen vivir". La revisión bibliográfica juega un papel importante para contrastar los cambios que se han dado a lo largo de los años en la movilidad de la población.

Las ciudades no mueren, crecen y se transforman, como consecuencia de la economía local, las necesidades de sus habitantes y de la capacidad de respuesta de las entidades que tienen competencias sobre el mejoramiento de su calidad de vida. Producto del crecimiento, la ciudad ha buscado implantar un mecanismo que represente mayores beneficios en términos de tiempo, dinero y calidad del servicio, pero tal vez dejando de lado el estudio de esas particularidades que denotan un respeto por el entorno construido (Naranjo, Y \& Arellano, B., 2018).

En conclusión, en la ciudad de Guayaquil desde la empresa de carros urbanos hasta el sistema de Transporte público masivo Metrovía se han obtenido grandes cambios, sin embargo, esos cambios no han ofrecido, ni han garantizado una movilidad que permite establecer intermodalidad o que genere espacios donde el peatón sea el principal protagonista. El plan de movilidad planteada entre sus metas y acciones mencionaba un proyecto con equidad,

\footnotetext{
${ }^{1}$ Arq. M.Sc. Universidad Católica de Santiago de Guayaquil, UPC; ${ }^{2}$ Arq. Blanca Arellano, MSc http://orcid.org/00000001-7128-3667; ${ }^{3}$ Dr. Arquitecto, Director del CPSV https://orcid.org/0000-0003-3970-6505. Correo de contacto: yelitza24@hotmail.com.
} 


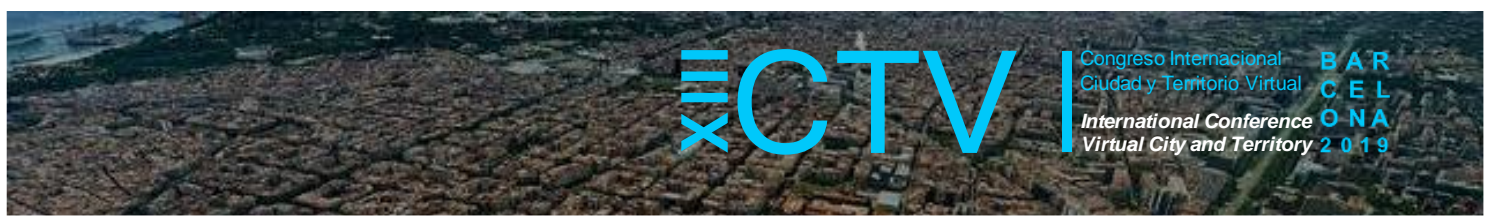

integración, equilibrio y articulación de los diferentes modos de transporte, sin embargo, hasta este año no se han dado estas mejoras.

\section{Abstract}

The entire process of urban renewal generates an impact on a social, physical, economic, environmental level and depending on the particularities of the context, defining the most specific strategies to develop a project, especially those that are directly linked to transport in cities (Naranjo, Y. \& Arellano, B., 2018).

Guayaquil and its urban transport have been linked to the growth of the city due to the increase in its population and its economy to the fines of the 19th century. The city and its center were sometimes in a process of commercial densification from the 1960s. Previously, its relationship with the Guayas River, a fundamental reason for its creation and existence, which ceased to be vital due to the decrease in economic activities that take place on the banks of the river. All these events associated with a growing migration of the population to the new residential neighborhoods developed in the periphery, and laid the groundwork for a decrease in the city center, largely limited to banking and public commercial activities.

In 2006, the Municipality of Guayaquil, implemented the integral Urban Mass Transportation System "Metrovía" and the city began to be subject to new physical transformations, in this case with the implementation of the new mass public transport system, which corresponds to a BRT (Bus Rapid Transit) system presented with sustainable visions, that is to say reduction of vehicular congestion, movement of greater amount of passengers and in less time than urban buses, reduction of environmental pollution and comfort in its displacement.

Its main objective is to analyze the impact and changes that have taken place in the urban structure of Guayaquil with transport, an investigation that aims to justifiably understand the parameters mentioned above, in turn the desire to know the mobility of the city as the main actor of public space, the way people are placed and moved from one place to another on foot, by bicycle or in a mass transit system.

The methodology used is qualitative - descriptive, with sources of information posed by a review of the current "Guayaquil mobility plan", the goals and actions that have been established and to what extent they have been implemented or developed, as well as contrast with the objectives that the Government has raised in the public document of the "Plan of Good Living". The literature review plays an important role in contrasting the changes that have occurred over the years in the mobility of the population.

Cities do not die, grow and transform, as a result of the local economy, the needs of their inhabitants and the response capacity of the entities that have competences on the improvement of their quality of life. As a result of growth, the city has sought to implement a mechanism that represents greater benefits in terms of time, money and quality of service, but perhaps leaving aside the study of those peculiarities that denote a respect for the built environment (Naranjo, $Y$ \& Arellano, B., 2018).

In conclusion, in the city of Guayaquil, from the urban car company to the Metrovía mass public transport system, great changes have been obtained, however these changes have not offered, nor have they guaranteed a mobility that allows intermodality to be established or that generates spaces where the Pedestrian be the main protagonist. The mobility plan raised between its goals and actions mentioned a project with equity, integration, balance and articulation of the different modes of transport, however, until this year there have been no such improvements.

Palabras Clave: estructura; imagen urbana; transporte; movilidad

Key words: structure; urban image; transport; mobility

\section{Orígenes del transporte en la ciudad}

La ciudad de Guayaquil ubicada a orillas del río Guayas, se desarrolló en sentido norte - sur, aprovechando la fácil comunicación que permitía el río, ya que se encontraba ligada directamente al sistema de transporte que en un principio se desarrollaba mediante el sistema fluvial balsas, balandras y navíos para salir al mar. 


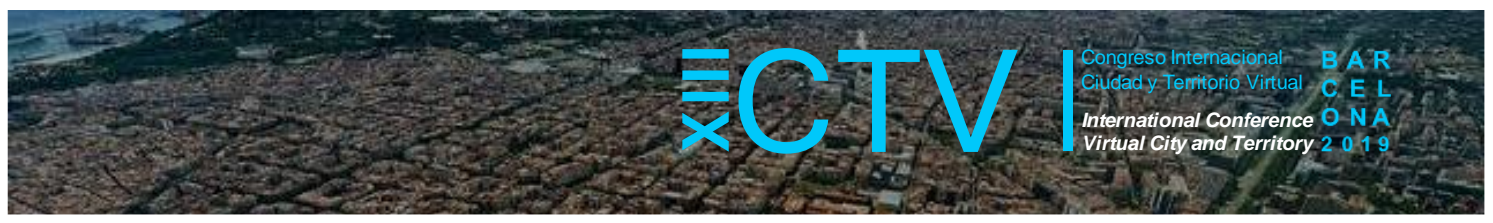

La ciudad se extendía del Camal en el sur a las Peñas en el norte, con poco ancho en sentido este-oeste, el crecimiento hacia el oeste tuvo lugar en los años 40 cobrando impulso con la urbanización sin planificación adecuada y las primeras invasiones de tierra.

Las zonas densamente pobladas del sur y suroeste proporcionaban trabajadores a las industrias situadas hacia el norte o hacia el este causando que el transporte masivo haga largos recorridos por la ciudad.

El puerto marítimo al sur y el puente sobre el río guayas al norte, ocasionó que las mercaderías y el tránsito extra pesado generado por el puerto, recorra también la zona céntrica de la ciudad. La ubicación del aeropuerto y Terminal Terrestre al norte de la ciudad también obligaba a los numerosos usuarios del sur a cruzar toda la ciudad. La concentración administrativa, comercial y bancaria en la zona central obligaba a las unidades de transporte a pasar por pocas calles, este problema disminuyó por la descentralización de servicios hacia urbanizaciones periféricas. (Memorias, Guayaquil 2000, 1988)

Figura 1. Plano de Guayaquil

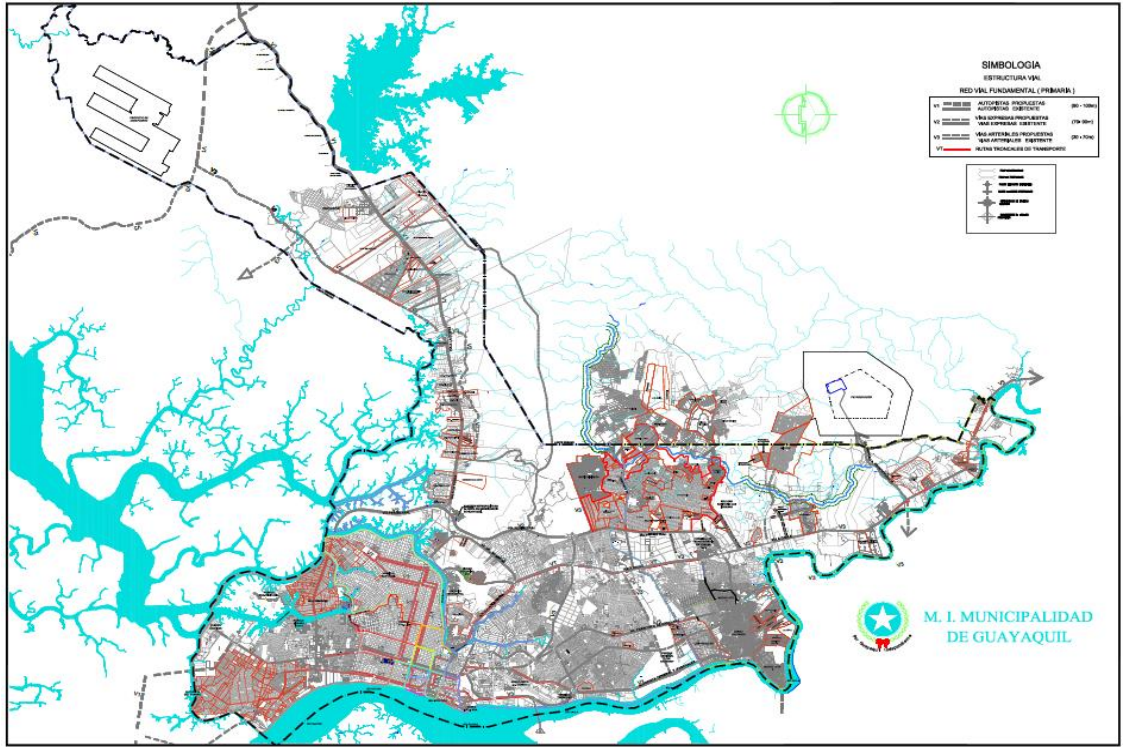

Fuente: Huerta, 2014

\section{Transporte e Imagen Urbana a través de los años en la ciudad de Guayaquil.}

\subsection{La empresa de carros urbanos}

El transporte urbano ha estado íntimamente ligado al crecimiento de la ciudad desde hace 115 años, a raíz del incremento de su población y de su economía a fines del siglo XIX, con el auge cacaotero. Esos primeros carros urbanos que tirados por mulas entraron a funcionar en $1880 \mathrm{y}$ en 1884 circulaban por el Malecón los carros imperiales" que tenían una banca doble en el techo, al cual se legaba por una escalera (Estrada Icaza, 1995). Este servicio de transporte no fue seriamente regulado sino hasta 1890, cuando el presidente de esa época ordenó que se elaborara un reglamento para ser manejado y ejecutado por los gobiernos seccionales y sus respectivas delegaciones policiales. (Hoyos G, Los Recuerdos de la Iguana, Historias del Guayaquil que se fue, 2008). 


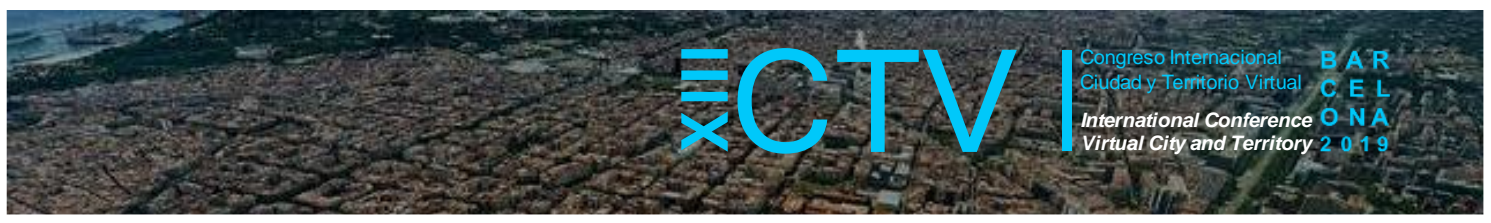

Figura 2. Guayaquil, alrededor de 1900. Mirando hacia el norte. Río

Guayas está a la derecha

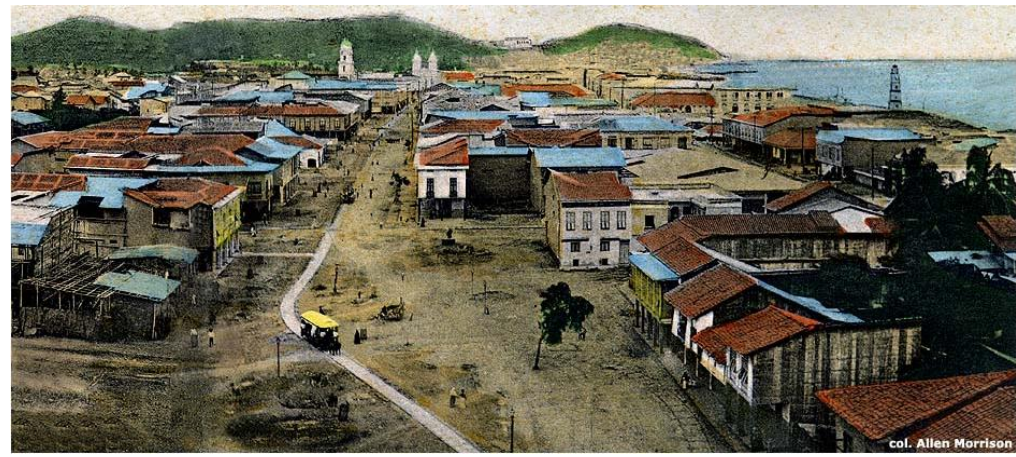

Fuente: Morrison, 2008

En la figura 2 se puede observar cómo se empieza a dar el sistema de transporte en la única calle empedrada que se hace parte de este sector, un eje importante para que las personas puedan trasladarse de un extremo a otro de la ciudad.

\section{Figura 3. Fotografía Carros Urbanos}

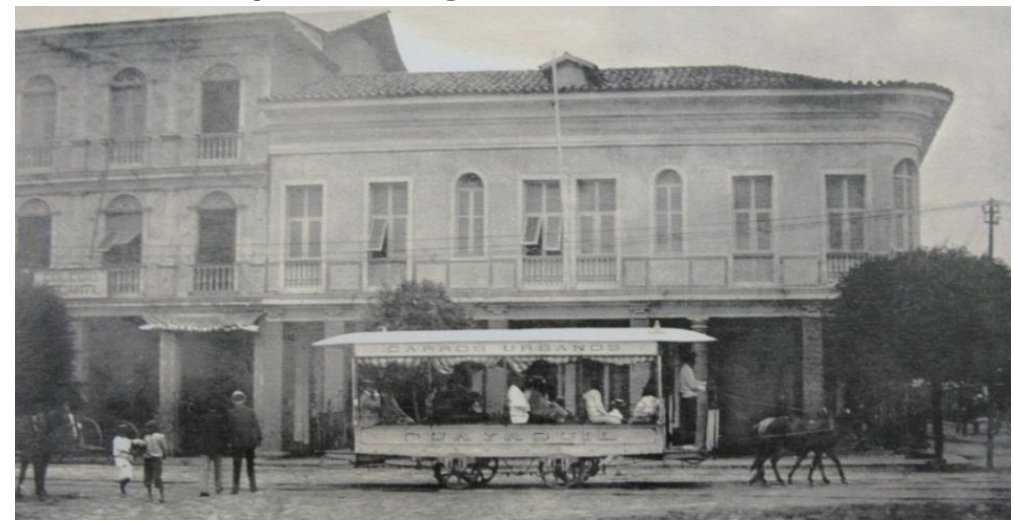

Fuente: Hoyos G, Los Recuerdos de la Iguana, Historias del Guayaquil que se fue, 2008

En la figura 3 se observa los carros urbanos que se utilizaban como transporte, la relación directa que se da con las viviendas, la infraestructura, el entorno urbano y a su vez la presencia de vegetación que se da en las aceras de las diferentes vías.

Es así como luego la creación de la empresa de Carros Urbanos en 1885 renovó drásticamente el transporte público, en un tiempo en el que la ciudad ya sentía sus falencias. Esta definitivamente se perfiló desde su inicio como un gran negocio, pues al poco tiempo de fundada compró la Empresa del Salado y con ella la línea que llegaba hasta los Baños del Salado (posteriormente American Park y hoy Parque de Guayaquil), para luego adquirir la del hipódromo, al sur de la ciudad.

La creación de la empresa se hizo con capitales privados y fines de lucro, obedeció desde sus inicios a un acuerdo entre la Municipalidad y la sociedad formadora de la misma, con el fin de dotar a Guayaquil de un servicio de transporte acorde con su crecimiento (Hoyos G, Los Recuerdos de la Iguana, Historias del Guayaquil que se fue, 2008). 


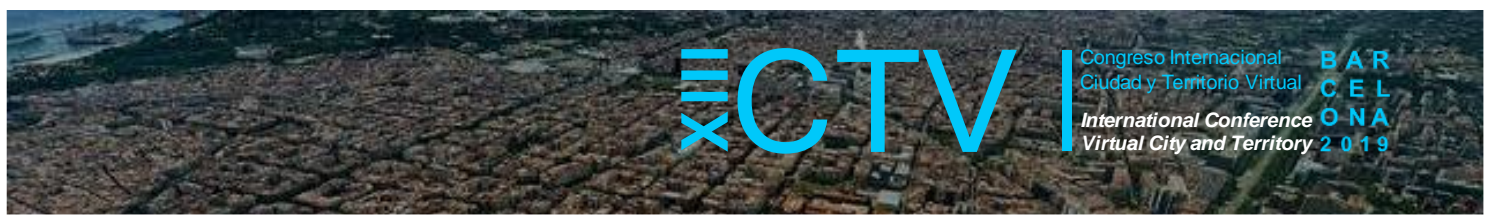

Figura 4. Iglesia de la Merced, 1896 (Rocafuerte y V.M. Rendón)

Fuente: Allen Morrison

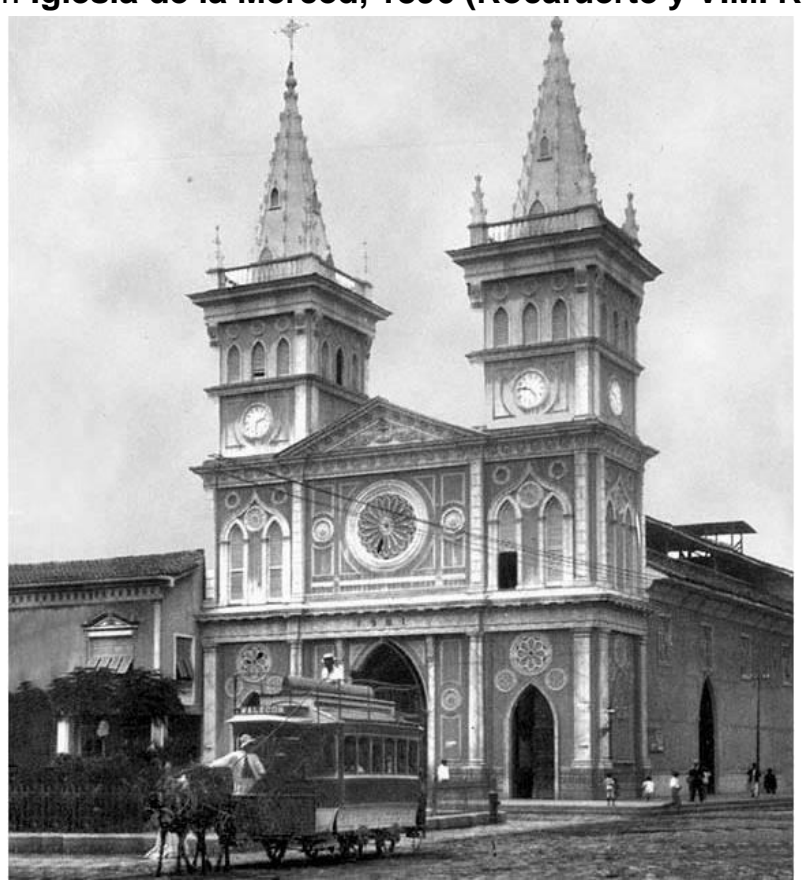

El crecimiento experimentado por la Empresa de Carros Urbanos fue constante y sostenido, razón por la cual en 1904 una nueva empresa, formada por los sr. Rohde y Guzmán, les propuso entrar en sociedad, dándoles a conocer que han terminado las gestiones necesarias para la instalación de tranvías eléctricos. El análisis detallado y concienzudo de dicha sociedad, basados en una multiplicidad de argumentos que iban desde la inconveniencia económica, pasando por complicaciones de tipo legal hasta llegar a prever que las instalaciones para el funcionamiento de un tranvía eléctrico provocarían con seguridad "por lo menos un incendio al mes, lo que haría peligroso y sumamente antipático el nuevo servicio" (Hoyos G, Los Recuerdos de la Iguana, Historias del Guayaquil que se fue, 2008)

La ciudad seguía manteniendo su visual al Río el mismo que seguía siendo su principal recurso económico, la figura 5 nos permite observar el desarrollo de la arquitectura, entorno natural e infraestructura como parte principal de lo que en esa época era la ciudad.

Figura 5. Malecón de Guayaquil, 1900-1910

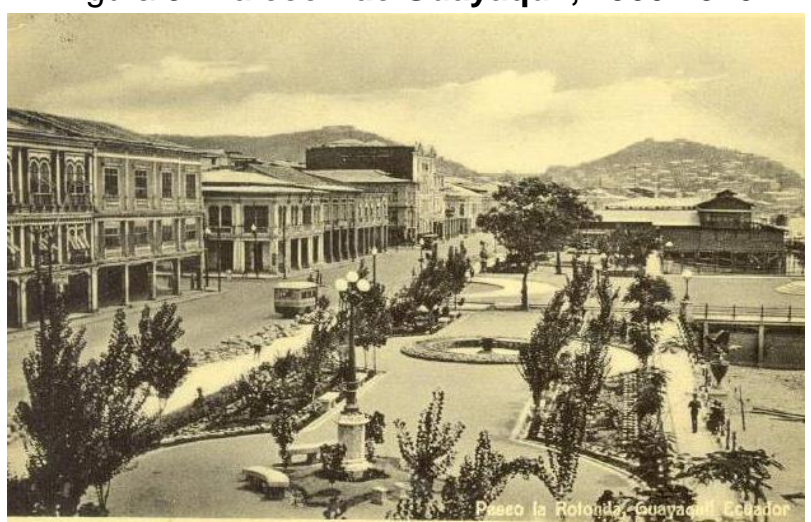

Fuente: SCView\&Sons 


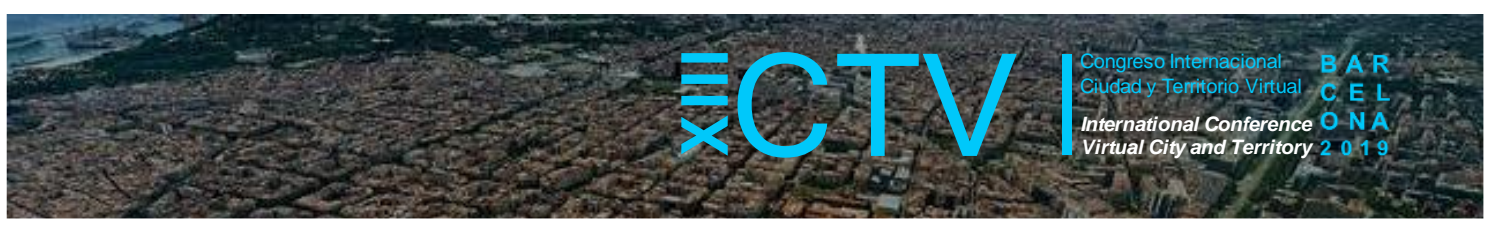

En 1907, la ciudad contaba con 56 líneas de carros urbanos que recorrían 33.000 metros. El tren rotatorio de la empresa estaba constituido por 15 carros "imperiales" (diferenciados de los demás por poseer dos pisos), 6 "jardines", 10 mixtos, 12 cerrados, 6 "góndolas" (llamados así por no tener techo), 3 carrozas y 20 carros para carga, lo que sumaba 72 vehículos que conducían diariamente a un promedio de 20.000 pasajeros.

Para ese entonces las principales líneas existentes en la ciudad eran las del Malecón, Astillero, Matadero, Victoria, Cementerio, Salado, Morro, Chanduy, Hipódromo y Luque. Era pues la ciudad el lugar perfecto para invertir en este negocio. Pero el tiempo pasó y la empresa comenzó a ver tinte de oscuridad en su horizonte, principalmente por no haber aceptado en su momento la implementación de los tranvías eléctricos (Hoyos G, Los Recuerdos de la Iguana, Historias del Guayaquil que se fue, 2008).

\subsection{El tranvía eléctrico en Guayaquil}

La figura 6 nos muestra un plano con el recorrido del sistema de transporte de tranvía eléctrico y de los otros sistemas existentes de la época, líneas que respondían a los ejes principales del centro de la ciudad y que permitían fácil conexión a los diferentes puntos de la ciudad.

\section{Figura 6. Plano de Guayaquil con la identificación de las rutas del tranvía}

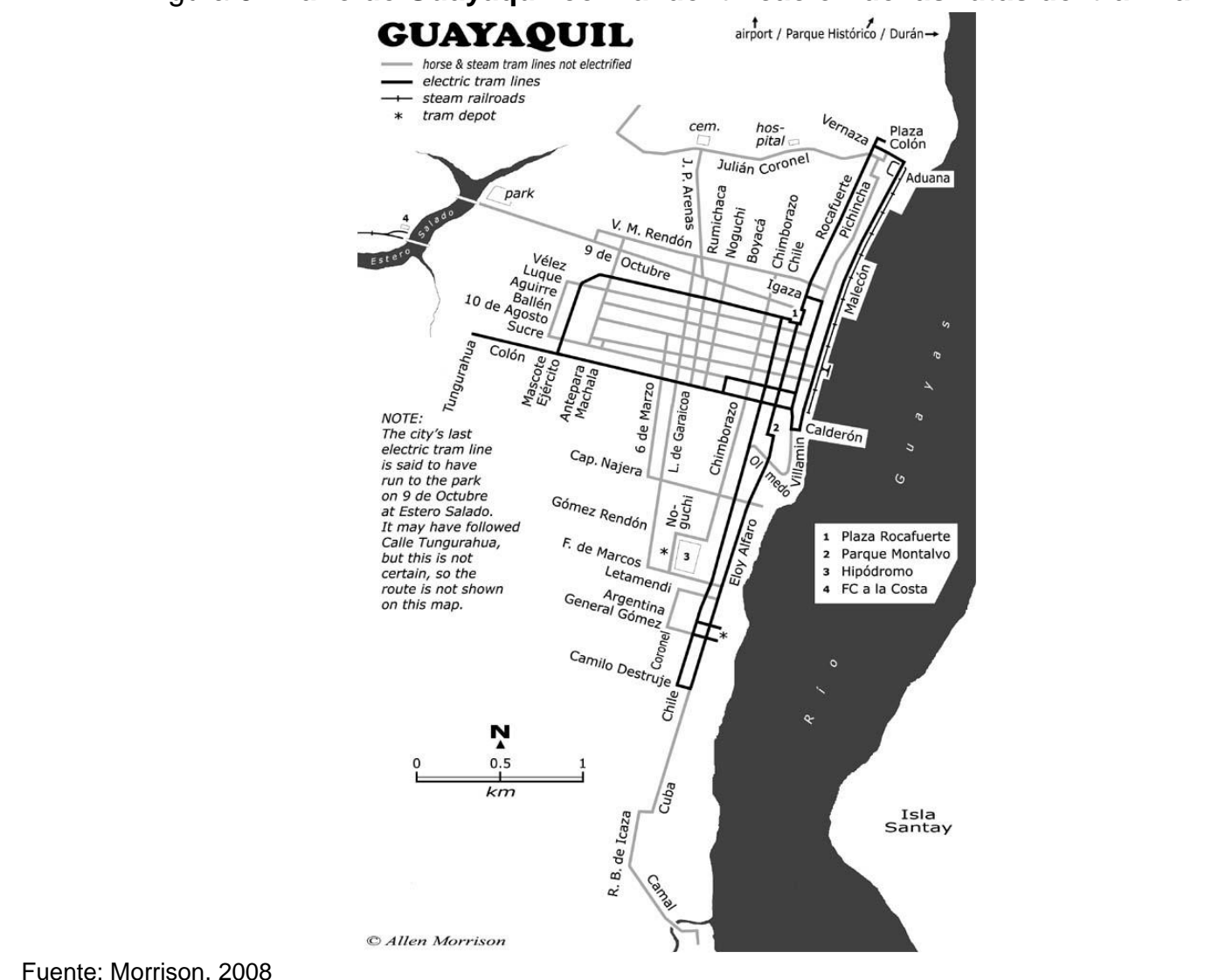

Fuente: Morrison, 2008

A principios del siglo XX aparece el tranvía eléctrico que empieza a funcionar en 1910 y ofrecía mayor comodidad, lo que provoca la caída de las acciones de la empresa de Carros Urbanos S.A., afectada también por la crisis económica de los años 20. 


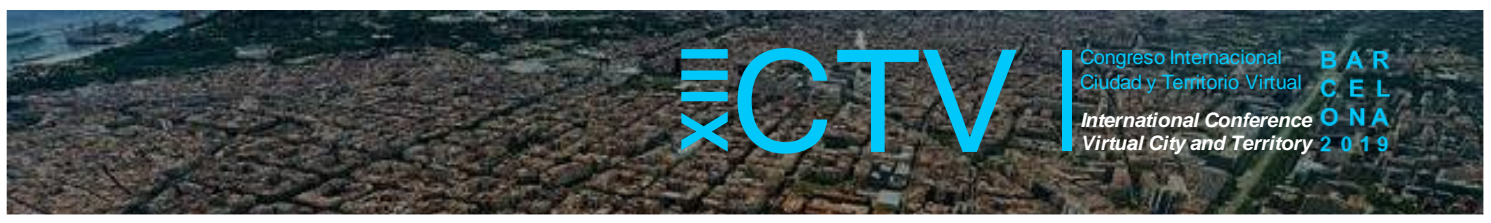

\subsection{El autobús}

Ocho años después (1918) quebró la empresa de carros urbanos y luego de 13 años liquidó la empresa de Tranvías Eléctricos. Según García y Villavicencio, en 1922 llegaron los primeros autobuses, importados por don Rodolfo Baquerizo Moreno, para 30 pasajeros sentados; el pasaje costaba cinco centavos. En 1929 nació la primera empresa de autobuses con la tarifa de diez centavos (Díaz \& Vega, 2012). A pesar de los diferentes sistemas de transportes que hasta la época se venían incorporando pero que de la misma manera desaparecían, la ciudad seguía manteniendo sus principales características y sus principales servicios administrativos, la accesibilidad, relación directa al entorno natural y social como se muestra en la figura 7.

Figura 7. Plano de Guayaquil con la identificación de las rutas del tranvía

Fuente: SCView\&Sons

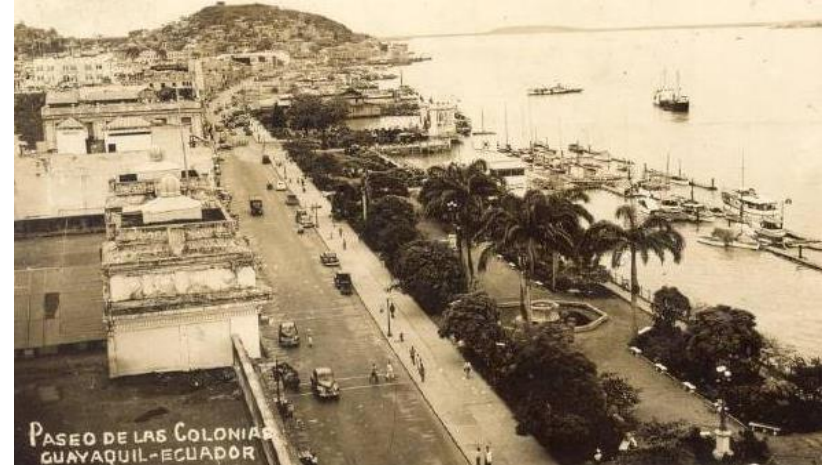

\subsection{El colectivo}

En 1940 creció el parque automotor de buses; en 1947 aparecieron los colectivos; la primera versión fue los Station Wagon en que se iban seis personas sentadas y el pasaje costaba un sucre. Como la demanda aumentó se adaptaron carrocerías para convertirlos en vehículos tipo micro para 16 personas (Díaz \& Vega, 2012). La figura 8 intersección de la calle Pedro Carbo y Eloy Alfaro, en la que se observa no solo la dimensión de esta vía, sino también su trazado urbano es decir que el paso de los sistemas de transportes podía apreciar el entorno arquitectónico tanto de las viviendas como de cualquier otro edificio público que se encontraba en estas secciones de vías.

Figura 8. Calle Eloy Alfaro 1930-1940

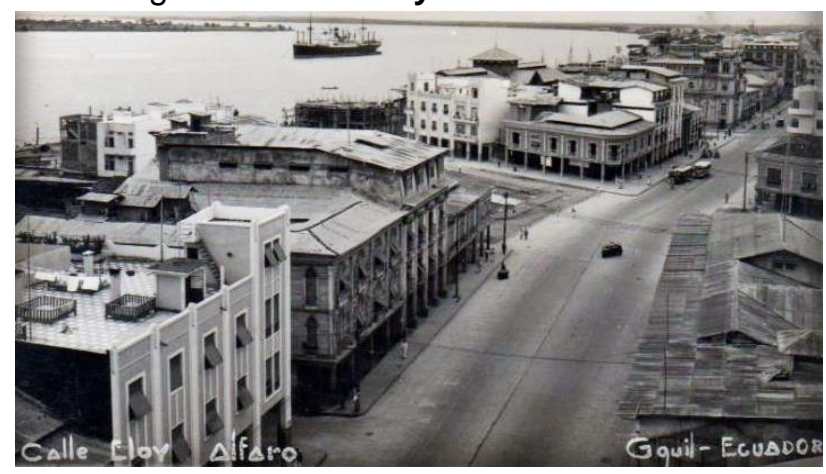

Fuente: Guayaquil, Fotografias antiguas, Skycrapercity 


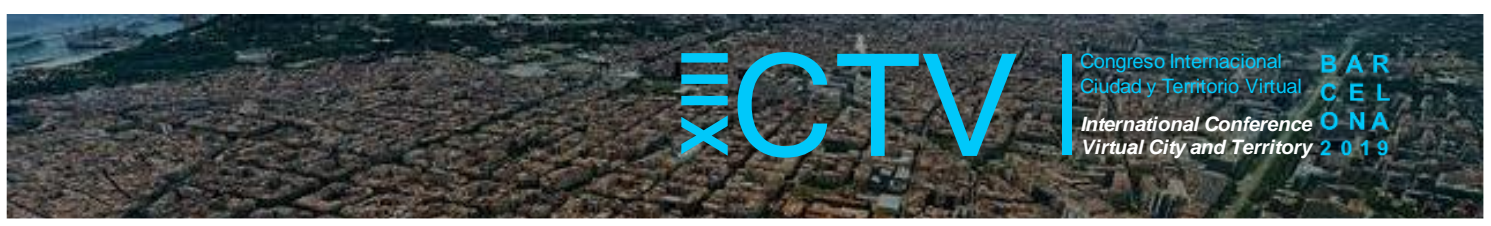

En 1950 ya hubo 145 unidades, el crecimiento de los buses y colectivos no fue igual. En la década del cincuenta los colectivos aumentaron con relación a los buses $(78 \%$ ) y en el año 60 se sigue dando el mismo aumento de los colectivos y los buses a su vez disminuyeron en el 3\%. (Díaz \& Vega, 2012)

De esta manera en la década del 50 se empezaron a desarrollar nuevas urbanizaciones en la ciudad, debido al crecimiento poblacional que se generaba, todo esto ocasionó que aumentara el transporte para poder abastecer a la población sobre todo en los asentamientos populares que existían hasta esa época. En la figura 9 se observa mayor afluencia vehicular, en la avenida 9 de octubre, la sección de la vía, el recorrido que realiza las personas, pero a su vez nos permite identificar los diferentes hitos, la vegetación que conservan estas avenidas y la arquitectura en este eje importante de la ciudad.

Figura 9. Boulevard 9 de octubre, 1950

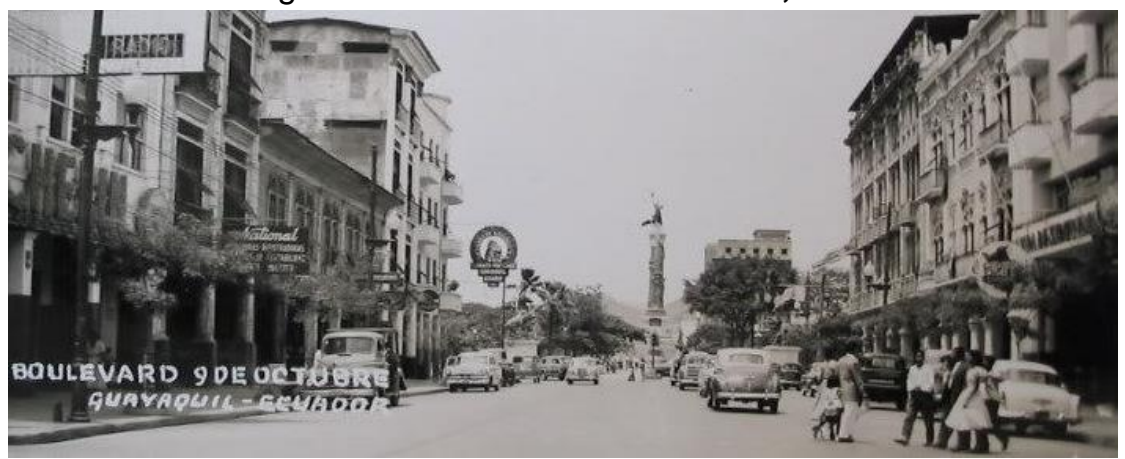

Fuente: Guayaquil, Fotografias antiguas, Skycrapercity

La evolución de los límites urbanos de la ciudad desde 1928 hasta 1955, se da al mismo tiempo que los cambios en los sistemas de transportes, es decir estos sistemas a lo largo de los años se han ido adaptando a la ciudad y a su trama urbana, incluso respetando las nuevas urbanizaciones que empezaron a desarrollarse en esa época, respetando la topografía natural, sin alterar su imagen y entorno urbano (Naranjo, Y. 2014)

Figura 10. Plano de Guayaquil con la evolución de los límites urbanos 1928-1934-1955 y sus vías principales

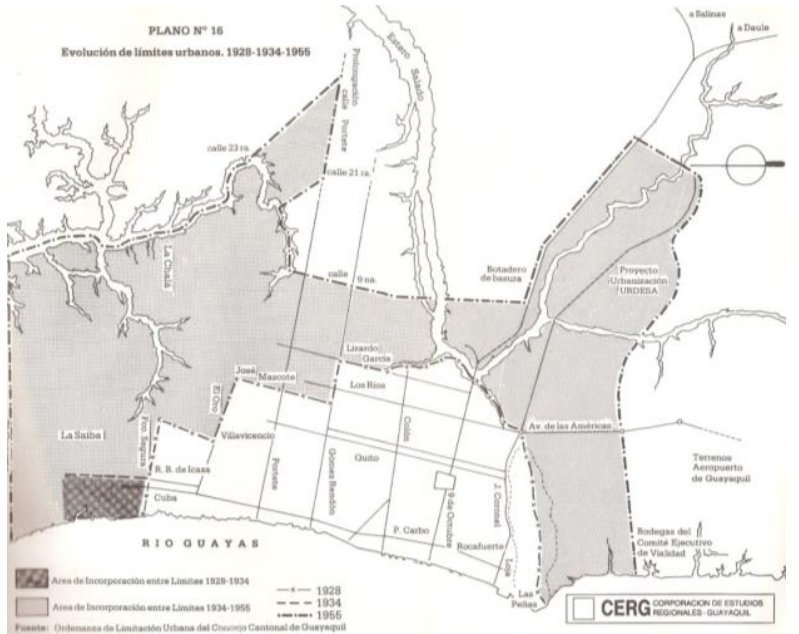

Fuente: Rojas \& Villavicencio, 1988 


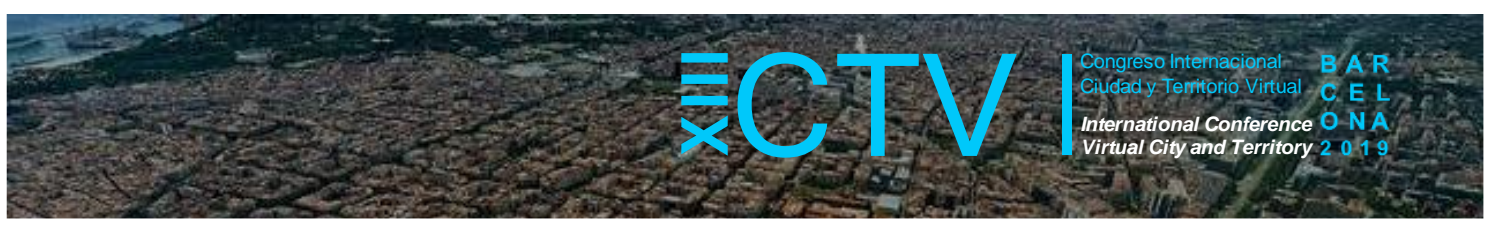

En la década de los 60 se trasladaron del Malecón y su centro urbano, las principales actividades portuarias al nuevo puerto al sur de la ciudad, la ejecución de los puentes que unieron Guayaquil con el resto del país, fueron algunos hechos fundamentales que asociados a la falta de planificación urbanística dieron inicio al proceso de degeneración del centro urbano. (Dreher A, 2009). Es a partir de entonces que la ciudad comienza a darle la espalda a uno de sus recursos más importantes: el gran Río Guayas. Paralelamente se produjo el abandono del centro urbano como zona residencial, además de una intensa densificación comercial, limitándose su uso al comercio y oficinas. En la figura 11 de 1958 del malecón Simón Bolívar de la ciudad se observa la presencia del vehículo privado a lo largo de este eje, y la relación directa que se mantenía con el río (Naranjo Y. 2014).

\section{Figura 11. Malecón Simón Bolívar, Guayaquil, 1958}

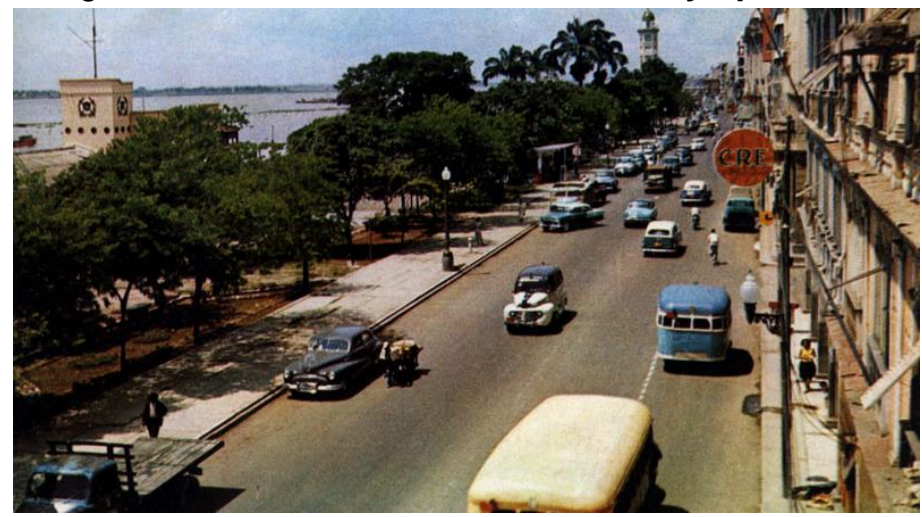

Fuente: Guayaquil, Fotografias antiguas, Skycrapercity

\subsection{La furgoneta}

En la década del setenta, surgió la furgoneta; consistía en una camioneta Pick Up con casera y tenía recorridos más directos, el pasaje era de dos sucres. Pero los transportistas de colectivo adquirieron unidades tipo buseta para 30 personas sentadas y hacían recorridos más cortos que el bus y colectivo (Díaz \& Vega, 2012).

Las imágenes 33 y 34 de 1960-1970 aprox., tanto en la calle Pedro Carbo como en Malecón observamos una mayor presencia del transporte público y privado, relación directa con el entorno natural y el entorno construido en este caso las edificaciones que están a lo largo de este eje (Naranjo Y. 2014).

Figura 12. Calle Pedro Carbo, 1960-1970

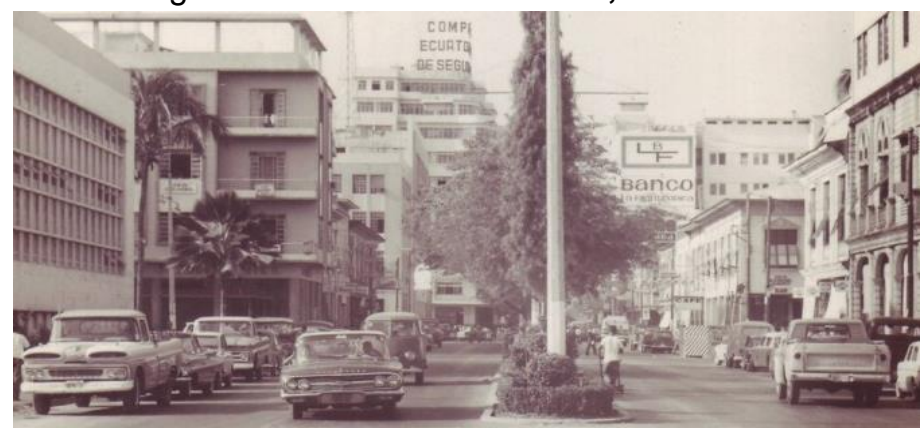

Fuente: Guayaquil, Fotografias antiguas, Skycrapercity 


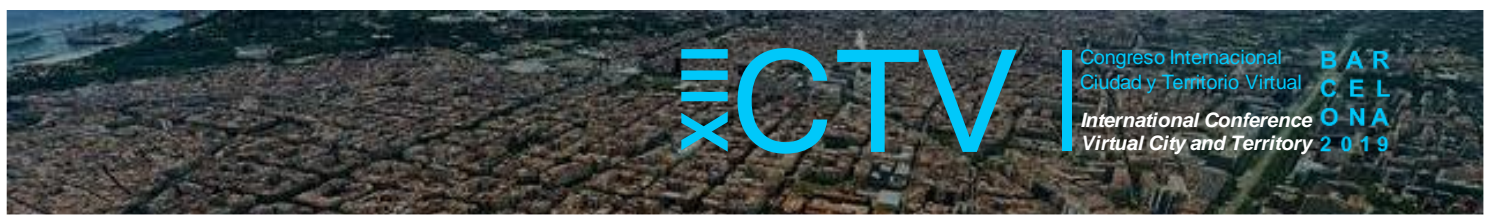

Figura 13. Vista Río Guayas, 1970.

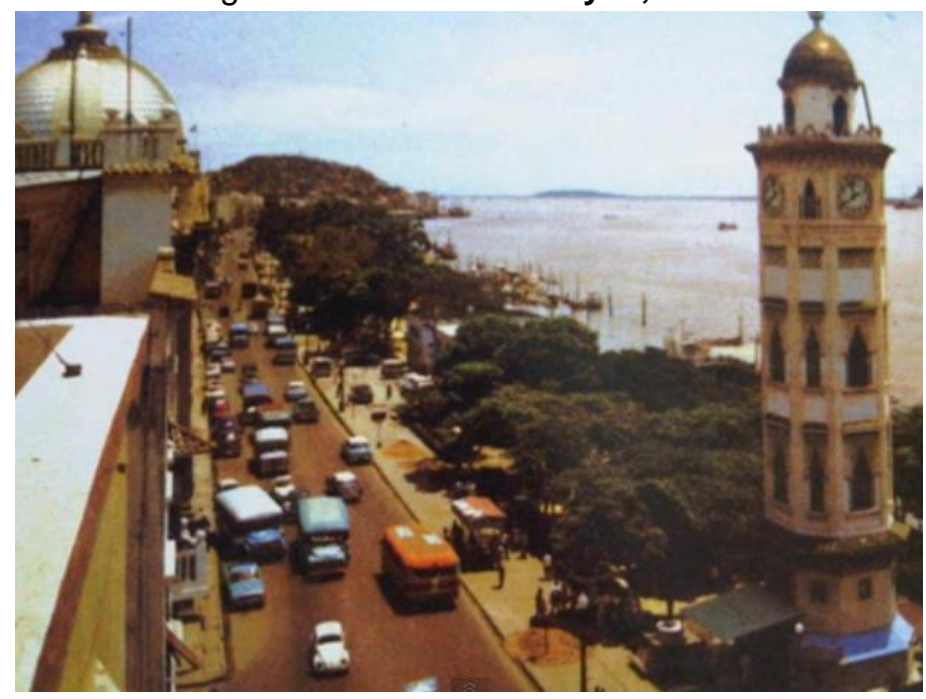

Fuente: SCView\&Sons

\subsection{El transporte urbano colectivo}

En 1975 ya existían 27 rutas de buses y diez años después era el parque automotor más alto de la ciudad (31\%), en 1976 se igualó el precio del pasaje, lo que provocó el incremento del segundo. En 1984 surgieron los colectivos especiales "solo sentados", la tarifa fue de ocho sucres, con relación a los buses cuya tarifa era de cinco sucres (Díaz \& Vega, 2012).

1990 taxis rutas, hacían recorridos puntuales de un lugar a otro sin paradas intermedias. En 1991 salen los Buses articulados, este servicio era manejado por la Comisión de Tránsito del Guayas (CTG), pero el servicio duró un poco más de un año, debido al problema de repuestos para estos vehículos (Naranjo Y. 2014).

1992 Las furgonetas recorren toda la ciudad con rutas más cortas y con mayor frecuencia y horario. Pero su capacidad era de solo 12 pasajeros, resultando caóticas para el tráfico en las zonas más convulsionadas (Casal C \& Romero C, 2009).

Figura 14. Guayaquil antes de la Regeneración Urbana

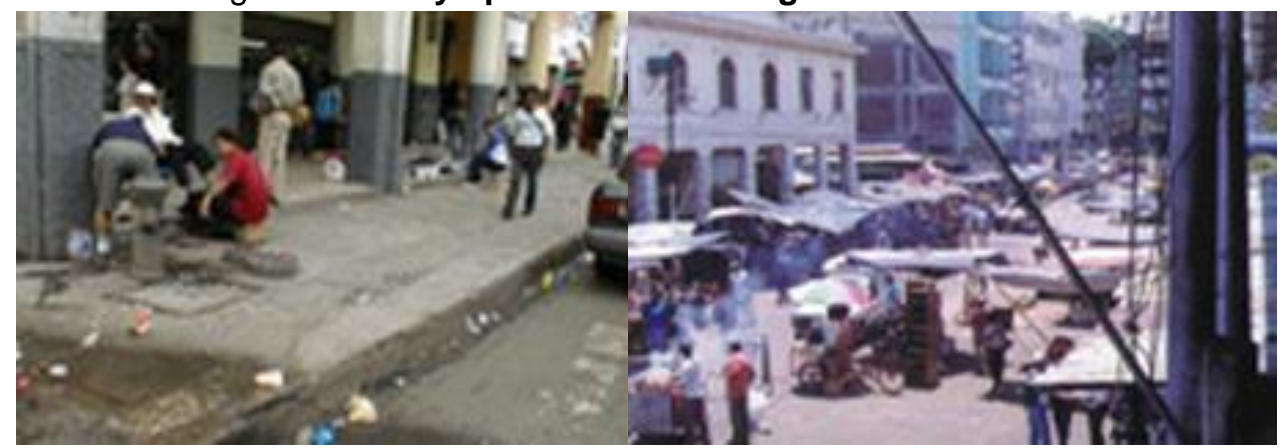

Fuente: Dreher, 2007

La ciudad de Guayaquil y su centro urbano estuvo sometida a un proceso de densificación comercial a partir de la década de los sesenta. Previamente su relación con el río Guayas, 


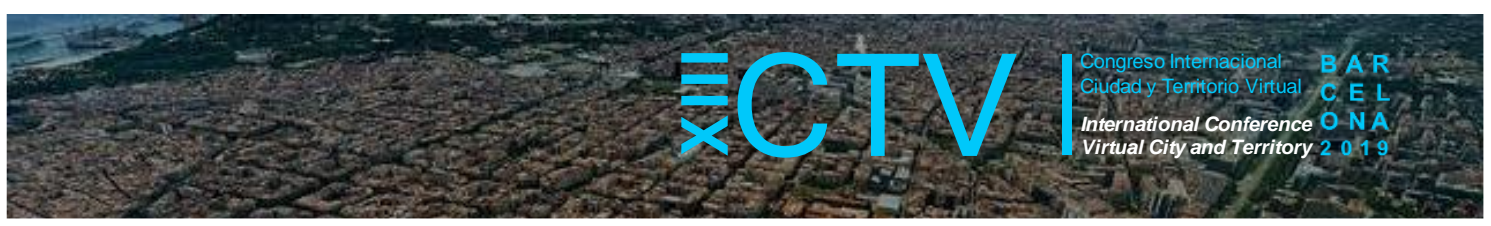

razón fundamental de su creación y existencia, había dejado de ser vital por la disminución de las actividades económicas que tradicionalmente se desarrollaban en sus orillas.

Este hecho asociado a una creciente migración de los residentes hacia los nuevos barrios residenciales desarrollados en la periferia sentó las bases para un deterioro del centro de la ciudad, limitándose en gran parte a las actividades comerciales, de oficinas es decir actividades bancarias y públicas (Revista Trama Digital, Malecones de Guayaquil).

En 1999 Se inauguró la primera etapa del Malecón, a lo largo del año 2000 - 2002 se inauguran las dos etapas restantes del malecón. La Regeneración Urbana se constituye como uno de los componentes para alcanzar los objetivos de un desarrollo sostenible de la ciudad, y es precisamente esta visión de sostenibilidad la que hace la recuperación de las infraestructuras urbanas, un medio donde coexisten tres dimensiones que, en conjunto, garantizan la sostenibilidad de una sociedad: la dimensión económica, la social, y la ambiental (Dreher, 2007).

La figura 15 nos muestra un antes y un después de la regeneración urbana a la que fue sometida la ciudad de Guayaquil en el año 2000, que logró mejorar la imagen urbana y a su vez recuperar espacios que estaban degradados (Naranjo Y. 2014).

Figura 15. Guayaquil antes de la Regeneración Urbana
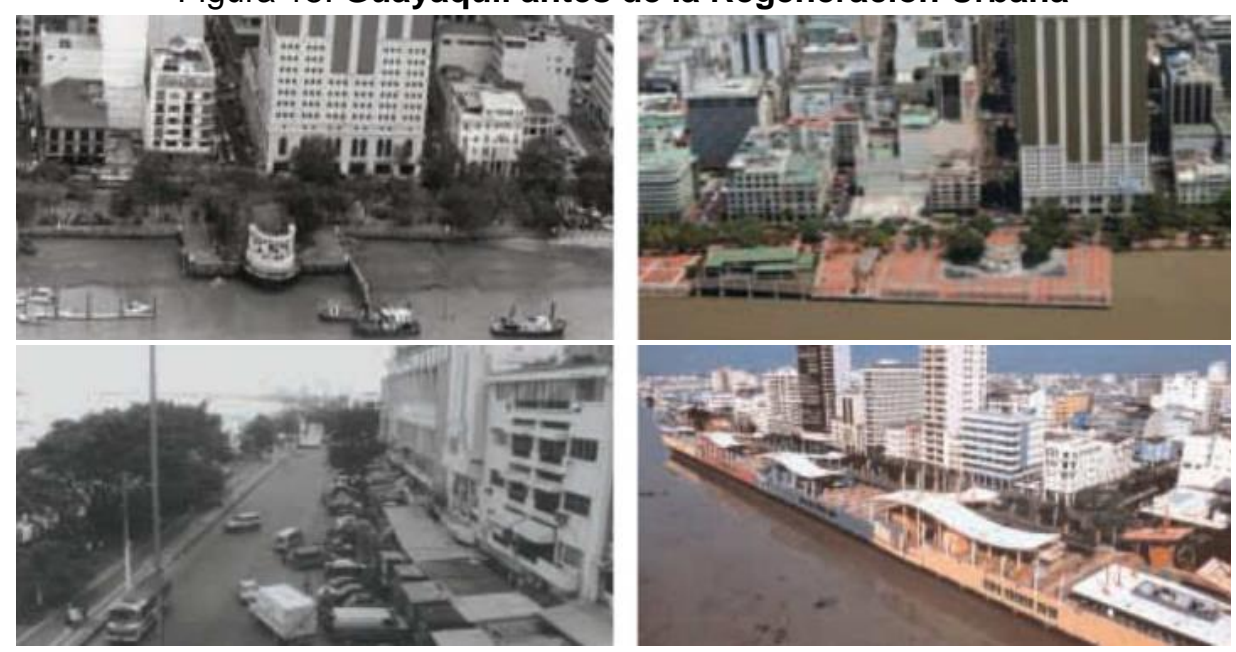

Fuente: Dreher, 2007

2001 El Consejo Nacional de Tránsito (CNT) y la Comisión de Tránsito del Guayas (CTG) resuelven el 12 de octubre del 2000 que, desde el 13 de abril del 2001, las furgonetas dejarán de brindar el servicio de transporte público (Naranjo Y. 2014).

2003 La CTG y el alcalde de Guayaquil, Jaime Nebot, promueven el cambio de colores e imagen en los buses de transporte urbano, servicio popular celeste y blanco y el especial azul y blanco (Casal C \& Romero C, 2009).

Para este año la ciudad había terminado las obras de regeneración urbana en ciertos sectores, sin embargo, no se veía una intención de reducir la congestión vehicular, que a su vez estaba siendo parte de la ciudad. 


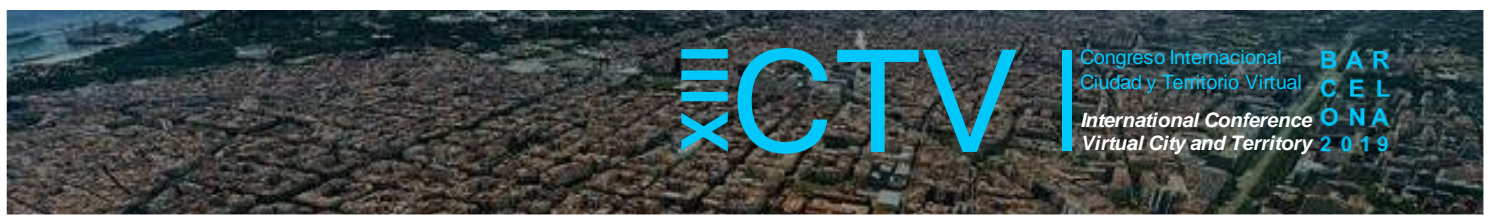

Figura 16. Buses Urbano Av. Machala

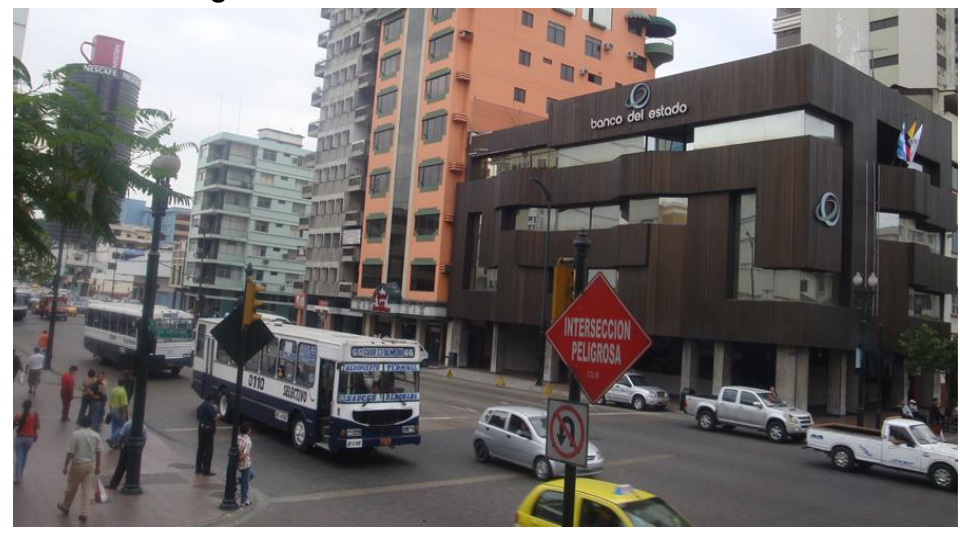

Fuente: Naranjo, 2014

\subsection{El sistema de transporte público masivo Metrovía}

- 2006 El Municipio de Guayaquil, implementó El Sistema Integral de Transporte Masivo Urbano "Metrovía" (Casal C \& Romero C, 2009).

La ciudad empezaba una vez más a ser sometida a transformaciones físicas, en este caso con la implementación del nuevo sistema de transporte urbano masivo, que en principio corresponde a un sistema BRT (Bus Rapid Transit) presentado con beneficios sostenibles, es decir reducción de congestionamiento vehicular, movimiento de mayor cantidad de pasajeros y en menor tiempo que los buses urbanos anteriores, reducción de la contaminación ambiental, y confort en su desplazamiento.

La figura 18 nos muestra como la ciudad ha tenido que ser adaptada a este nuevo sistema, no solo estableciendo un carril exclusivo en vías con poca dimensión, si no también espacios que deben ser considerados para las estaciones que están destinadas cada cierta distancia (Naranjo Y. 2014).

Figura 17. Terminal del Sistema de Transporte Urbano Masivo de Guayaquil.

Fuente: Naranjo, 2014

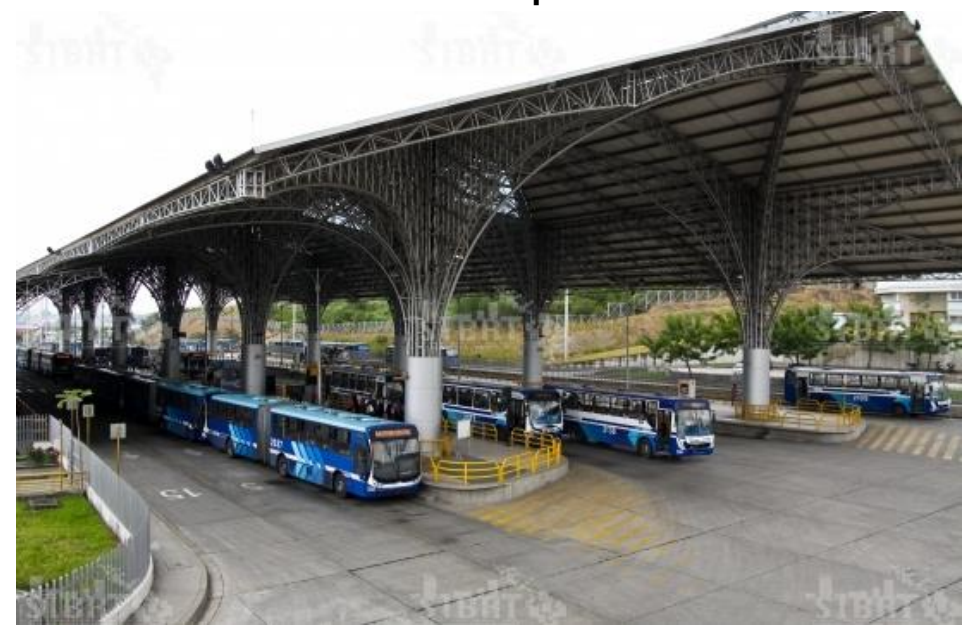




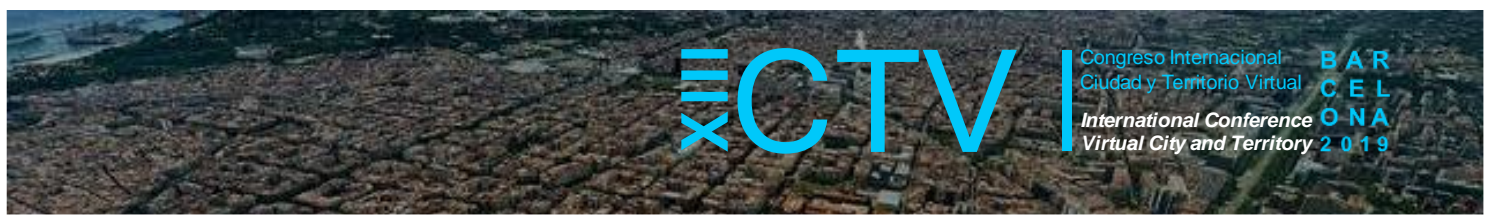

Figura 18. Eje Boyacá, Sistema de Transporte Urbano Masivo de Guayaquil

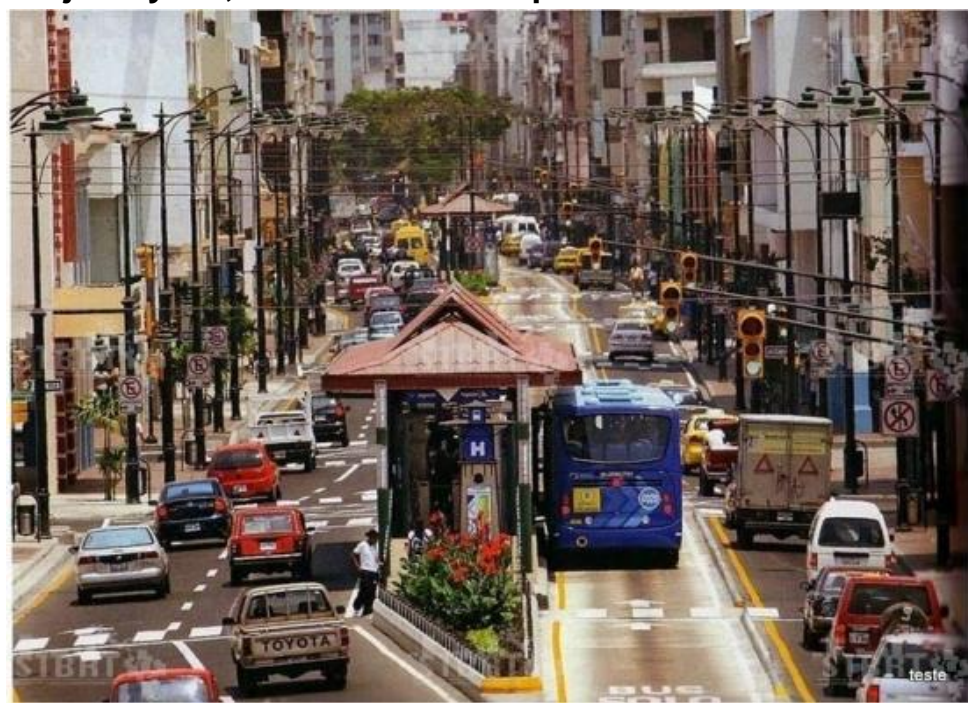

Fuente: Naranjo, 2014

- 2013 Sistema de Transporte Urbano Masivo y Buses Urbanos en la ciudad.

En la figura 19 observamos las diferentes líneas de buses que formaban parte de la ciudad y que han sido eliminadas de las zonas donde la Metrovía forma un circuito de recorridos, desplazando la congestión a otros sectores y no reduciéndola.

Figura 19. Buses Urbanos av. Quito.

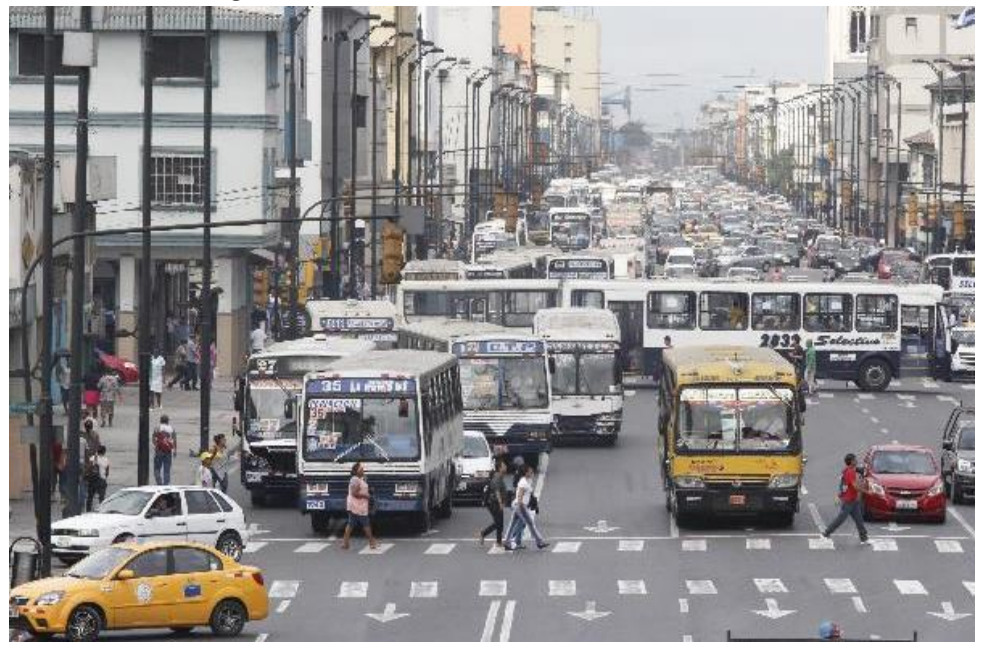

Fuente: Naranjo, 2014

En la figura 20 se muestra la ubicación de paradas en el denominado casco histórico de la ciudad, aquí se muestra una sección de vía con un elemento central implantado del sistema de transporte público masivo, con toda la infraestructura que implica, es decir, parada elevada a $0.85 \mathrm{~m}$, rampas de acceso y salida, señalización de cruces de seguridad peatonal y semaforización peatonal. (Naranjo Y. 2014). 


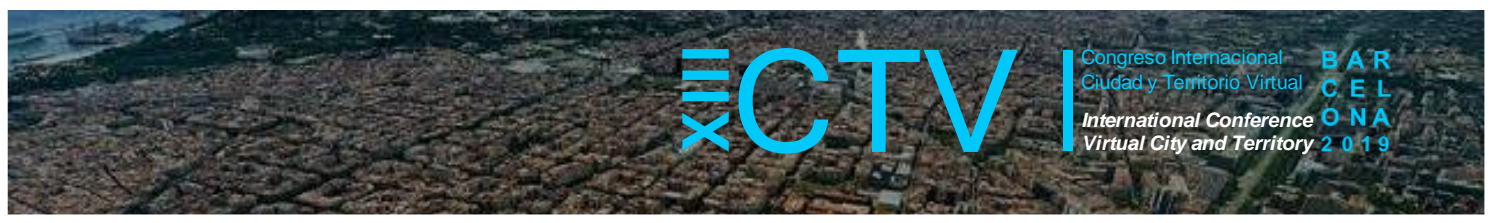

Figura 20. Paradas Metrovía, casco histórico de la ciudad

Fuente: Naranjo, 2018

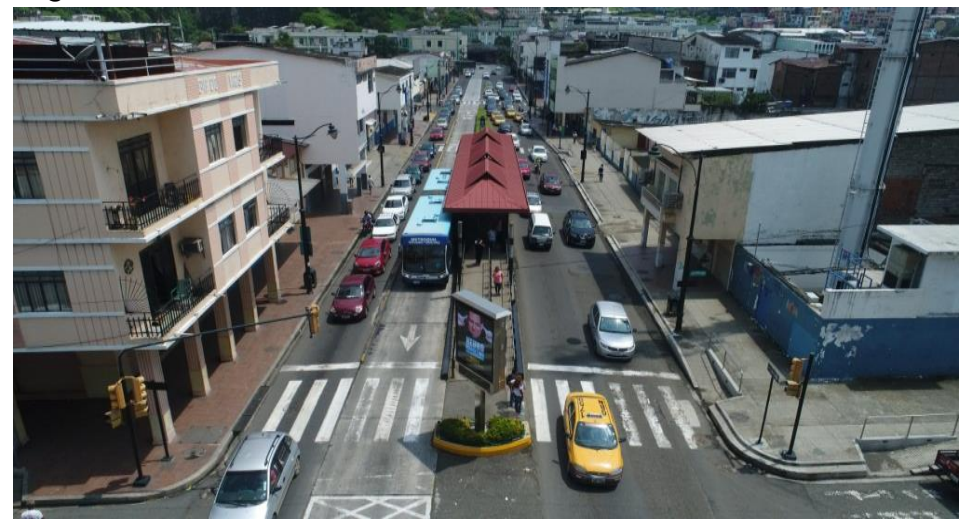

\section{Conclusiones}

En conclusión, en Guayaquil desde la empresa de carros urbanos hasta el sistema de Transporte público masivo Metrovía se han obtenido grandes cambios, sin embargo, esos cambios no han ofrecido, ni han garantizado una movilidad que permite establecer intermodalidad o que genere espacios donde el peatón sea el principal protagonista. El plan de movilidad planteada entre sus metas y acciones mencionaba un proyecto con equidad, integración, equilibrio y articulación de los diferentes modos de transporte, sin embargo, hasta este año no se han dado estas mejoras, por ejemplo:

- No existen desplazamientos seguros y se han aumentado los accidentes por el acceso de pasajeros, por la velocidad de los buses, etc.

- No existe una movilidad con sustentabilidad económica, ambiental, técnica y financiera.

- No se ha mejorado la calidad, disponibilidad, cobertura territorial y horario del servicio.

- Las metas mencionan que hasta el año 2017 el sistema de transporte público masivo tendrá en operación a 5 de las 7 troncales previstas, y una mejora de la calidad del servicio y del espacio público de la ciudad. Hasta el momento año 2019 existen 3 de las 7 troncales o de las 5 que debían estructurar.

- No existe una equidad en el uso de los espacios públicos de circulación.

- No se da la protección del medio ambiente, se sigue generando un impacto negativo por el combustible de los automotores utilizados en este sistema de transporte.

- No se ha desarrollado un equilibrio entre el modelo de desarrollo urbano y el modelo de movilidad.

- No existe creación de espacios mono funcionales, ni el uso creciente de modos no motorizados de movilidad.

Toda la infraestructura que se asigna es para el vehículo, quedando de lado el peatón y reduciendo su espacio para poder desplazarse o para poder realizar sus actividades en un espacio público seguro y eficiente.

Contribuciones de los autores: El primer autor ha desarrollado este documento desde las investigaciones de clases de la Maestría, el segundo y tercer autor ha sido guía, apoyo y ha contribuido a los diferentes capítulos para poder realizar con éxito esta ponencia. 


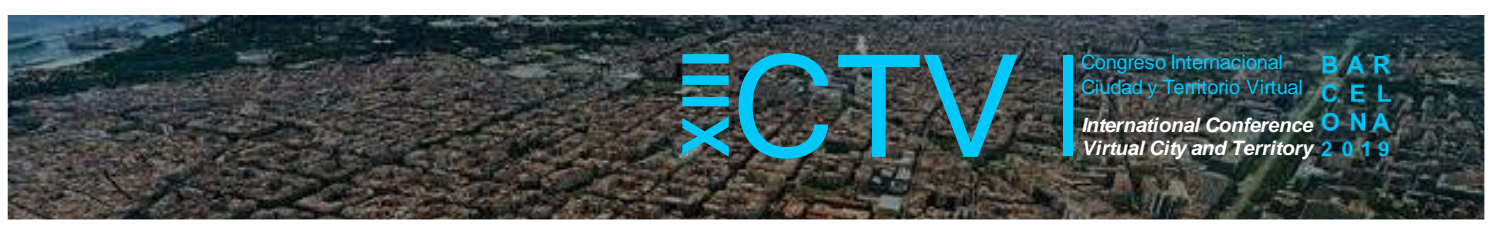

Conflicto de Intereses: Los autores declaran que no hay conflicto de intereses.

\section{Bibliografía}

Casal C, J., \& Romero C, J. (2009). Sistema Integral de transporte Masivo Urbano Metrovía: Integración del servicio al sector turístico. Guayaquil, Guayas, Ecuador.

Díaz, E., \& Vega, J. (diciembre de 2012). Estudio socioeeconomico de los usuarios de metrovía en la ciudad de Guayaquil y medición del Impacto de la Publicidad en el segmento. Guayaquil, Guayas, Ecuador.

Dreher A, D. (2009). Experiencia Guayaquil: Regeneración Urbana. La Ciudad viva como URBS, (pág. 1). Quito.

Estrada Icaza, J. (1995). Notas de un viaje de cuatro siglos, Guía Historica de Guayaquil. Tomo 1. Guayaquil: Poligrafica.

Hoyos G, M. (2008). Los Recuerdos de la Iguana, Hisorias del Guayaquil que se fue. Guayaquil.

Memorias, Guayaquil 2000. (octubre de 1988). Memorias. Guayaquil, Guayas, Ecuador.

Naranjo, Y. (enero de 2014). Impacto de la implementación del Sistema de la Metrovía en la trama urbana y las actividades del centro de Guayaquil. Barcelona.

Revista Trama Digital, Malecones de Guayaquil. (s.f.). Disponible en: http://www.trama.com.ec/espanol/revistas/articuloCompleto.php?idRevista=27\&numeroRevista $=97 \&$ articulold $=310$ 